Litvin, S.W., Goldsmith, R.E. and Pan, B. 2008. "Electronic word-of-mouth in hospitality and tourism management", Tourism Management, Vol. 29 No. 3, pp. 45868.

Park, D.H. and Lee, J. 2012. "eWOM overload and its effect on consumer behavioral intention depending on consumer involvement", Electronic Commerce Research and Applications, Vol. 7 No. 4, pp. 386-98.

Smith, D., Menon, S. and Sivakumar, K. 2014. "Online peer and editorial recommendations, trust, and choice in virtual markets", Journal of Interactive Marketing, Vol. 19 No. 3, pp. 15-37.
Sohn, D.Y. 2009. "Disentangling the effects of sosial network density on electronic word-of-mouth (eWOM) intention", Journal of Computer-Mediated Communication, Vol. 14 No. 2, pp. 352-67.

Steffes, E.M. and Burgee, L.E. 2009. "Sosial ties and online word of mouth", Internet Research, Vol. 19 No. 1, pp. 42-59.

Weinberg, B.D. and Davis, L. 2005. "Exploring theWOWin online-auction feedback", Journal of Business Research, Vol. 58 No. 11, pp. 1609-21. 
memenuhi kebutuhan dari pasar. Dalam menyikapi bentuk pemasaran ini, bentuk tindakan atau respon yang salah dapat menyebabkan kehilangan pelanggan dan yang paling buruk bisa kehilangan bisnis itu. Perlu sekali memperhatikan eWOM karena proses penyebaran dan tingkat pengaruhnya sangat tinggi di dunia virtual. Diperlukan kemampuan untuk menilai eWOM oleh para pemasara karena hal ini menjadi penting untuk menghadapi tantangan bisnis yang makin lama makin berkembang terutama seiring berkembangnya tekonoligi dan internet. eWOM merupakan alat pemasaran yang sangat kuat yang mampu membawa pemasar dan peneliti untuk berkomunikasi dan berinteraksi dengan konsumen agar menciptakan pemahaman yang lebih baik akan kebutuhan pasar akan suatu produk tersebut.

\section{KESIMPULAN}

WOM merupakan topic popular yang ada dalam ranah penelitian pemasaran, eWOM relative baru dalam ranah ini. Dalam studi kali ini, penulis telah mengidentifikasi 94 artikel yang terkai eWOM dan menganalisis beberapa literatur tersebut yang berkaitan dengan eWOM. Klasifikasi framework dibangun berdadarkan perspektif IPO, dan hal ini digunakan untuk meneliti eWOM. Review ini dapat menjadi acuan untuk penelitian eWOM berikutnya dan menjadi acuan bagi peneliti dan praktisi. Hasil yang ditampilkan dalam paper ini adalah: (1) dengan keterlibatan dan pengaruh internet dan aktifitas jejaring sosial, tak diragukan lagi bahwa eWOM akan menjadi penelitian yang menarik untuk terus digali dalam beberapa tahun mendatang. Berdasar temuan penulis disebutkan bahwa eWOM merupakan hal yang menarik untuk diteliti demi kepentingan akademik dan praktisi; (2) dilihat dari sisi output, ditemukan bahwa eWOM sedikit berdampak terhadap citra merek. Sebagian dari jurnal yang menyebutkan bahwa eWOM mempengaruhi persepsi konsumen, dan sedikit berdampak terhadap kesadaran merek; (3) eWOM mungkin bisa memaksimalkan pemasaran namun juga dapat merusak keseimbangan reputasi dan citra merek ketika aktifitas tersebut menjadi tidak baik bagi organisasi. Kebanyakan peneliti terfokus pada peluang apa yang dihasilkan eWOM, dan sedikit sekali perhatian kepada ancaman dan tantangan dengan adanya eWOM; (4) eWOM bisa ditemukan dalam berbagai jaringan berbeda, blog, facebook, websites dan lainnya. Semua itu tergantung pada tujuan dan target dari segmennya, praktisi dapat memilih berbagai jaringan tersebut untuk hasil yang dia harapkan.

\section{DAFTAR PUSTAKA}

Bickart, B. and Schindler, R.M. 2011. "Internet forums as influential sources of consumer information", Journal of Interactive Marketing, Vol. 15 No. 3, pp. 31-40.

Chen, Y. and Xie, J. 2012. "Online consumer review: wordof-mouth as a new element of marketing communication mix", Management Science, Vol. 54 No. 3, pp. 477-91.

Cheong, H.J. and Morrison, M.A. 2008. "Consumers' reliance on product information and recommendations found in UGC", Journal of Interactive Advertising, Vol. 8 No. 2, pp. 1-29.

Cheung, M.Y., Luo, C., Choon, L.S. and Chen, H. 2009. "Credibility of electronic word-of-mouth: informational and normative determinants of on-line consumer recommendations", International Journal of Electronic Commerce, Vol. 13 No. 4, pp. 9-38.

Dwyer, P. 2007. "Measuring the value of electronic word of mouth and its impact in consumer communities", Journal of Interactive Marketing, Vol. 21 No. 2, pp. 63-79.

Goldsmith, R.E. and Horowitz, D. 2012. "Measuring motivations for online opinion seeking", Journal of Interactive Advertising, Vol. 6 No. 2, pp. 1-16.

Harrison-Walker, L.J. 2001. "The measurement of word-ofmouth communication and an investigation of service quality and customer commitment as potential antecedents", Journal of Service Research, Vol. 4, pp. 60-75.

Hennig-Thurau, T. and Walsh, G. 2013. "Electronic wordof-mouth: motives for and consequences of reading customer articulations on the internet", Journal of Electronic Commerce, Vol. 8 No. 2, pp. 51-74.

Hennig-Thurau, T., Gwinner, K.P., Walsh, G. and Gremler, D.D. 2013. "Electronic word-of-mouth via consumeropinion platforms: what motivates consumers to articulate themselves on the internet?", Journal of Interactive Marketing, Vol. 18 No. 1, pp. 38-52.

Huang, J. and Chen, Y. 2012. "Herding in online product choice", Psychology \& Marketing, Vol. 23 No. 5, pp. 413-28.

Klein, L.R. and Ford, G.T. 2013. "Consumer search for information in the digital age: an empirical study of prepurchase search for automobiles", Journal of Interactive Marketing, Vol. 17 No. 3, pp. 29-49.

Lee, K. and Lee, J.M. 2014. "Understanding the product information inference process in electronic word-ofmouth: an objectivity-subjectivity dichotomy perspective", Information \& Management, Vol. 46 No. 5,pp. 302-11. 


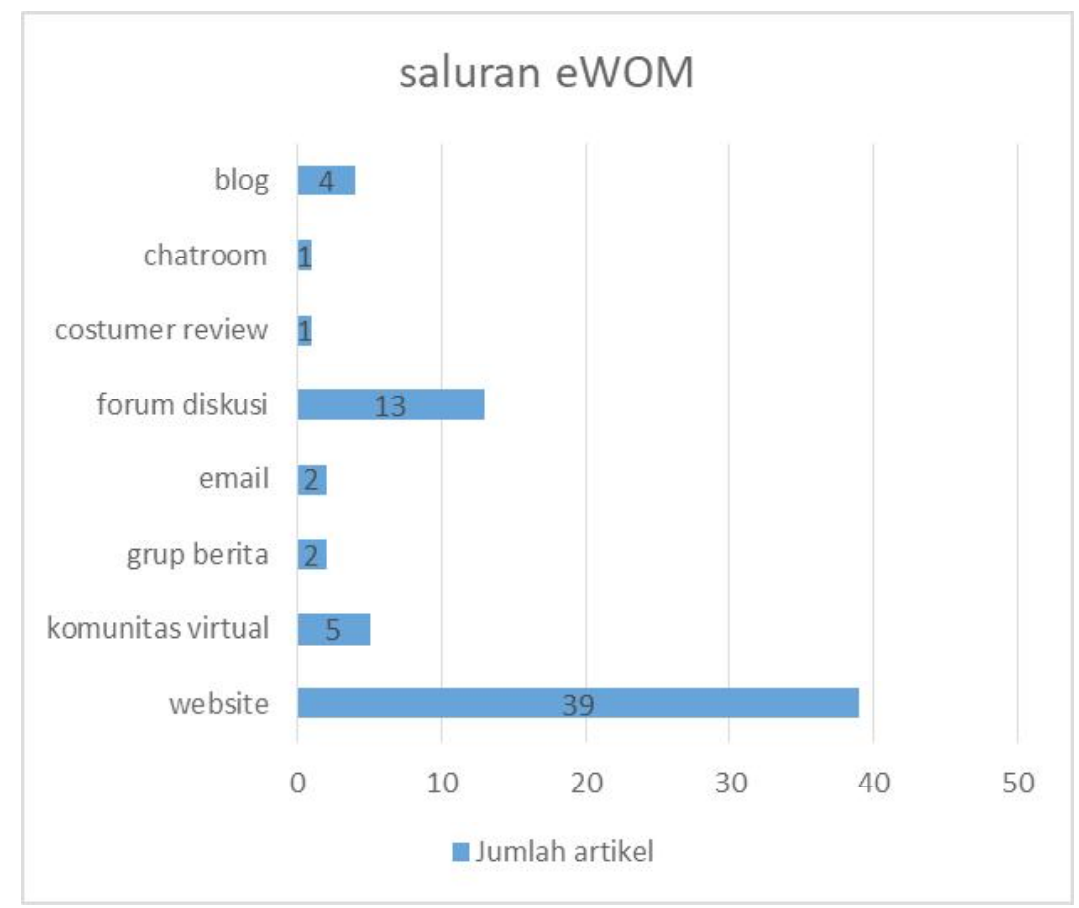

Gambar 4 Saluran eWOM

Banyak penelitian telah menyatakan komunikasi one-to-many (Forman et al., 2008; Harris dam Gupta, 2008; Casalo et al., 2008) dan many-to-many lebih sering dihasilkan ketimbang one-to-one. Contohnya, komunikasi one-to-one seperti email dan sms. Oneto-many, dimana menunjukan 41 persen dari total artikael menunjukan bahwa model ini yang sering digunakan dalam jaringan. Contohnya, seperti web sites, review produk, dan lain lain. Many-to-many, merupakan model komunikasi yang terbentuk dari blog, komunitas virtual, forum diskusi, dan lainnya. Gambar 4, menunjukkan bahwa website adalah saluran eWOM yang umum digunakan, yang selanjutnya diikuti oleh forum diskusi.

\section{Menyusun ke dalam IPO framework}

Ketika mengklasifikasikan artikel-artikel ditemukan bahwa beberapa dari makalah tersebut mewakili lebih dari satu atribut. Fokus yang dipillih adalah dimana mayoritas artikel tersebut terfokus. Analisis ini mampu mengklasifikasikan persepektif artikel tersebut. Diketahui bahwa kebanyakan peneliti tertarik dalam meneliti outcome dari eWOM. Dari 84 artikel 40 diantaranya terfokus pada meneliti outcome dari eWOM.

Penjualan produk dan keputusan pembelian merupakan area studi yang paling banayak diteliti untuk meneliti outcome eWOM. Totalnya ada 27 artikel yang terhubung dengan "proses" eWOM yang telah ditemukan, dimana hanya 17 artikel yang terkait dengan penelitian terkait "input". 17 artike (18\%) terkait dengan input menunjukkan bahwa penelitian tentang topic motivasi dari penulis, pembaca, atau pemasar dari eWOM. Motivasi pemasar mendapatkan sedikit perhatian dari para penliti. 27 artikel (32\%) yang terkait dengan proses menunjukkan hubungan antara input dan karakteristik pesan atau output juga karakteristik pesan yang disampaikan (soal negative eWOM dan kualitas eWOM).

Diantara kesemuanya, sistem rekomendasi yang menjadi perhatian terbesar. Juga ada sedikit pengaruh dari kualitas eWOM. 40 artikel yang teridentifikasi terkait dengan output fokus pada meneliti dampak dari eWOM terhadap keputusan pembelian juga penjualan produk, diikuti dengan implikasi oleh pemasar dan dampak kepada perilaku konsumen. Penelitian yang ada juga menunjukkan metrik eWOM, diterimanya produk, dan loyalitas pelanggan.

Penelitian Riegner (2007) menemukan bahwa ada tiga konten teratas terkait penciptaan aktifitas oleh konsumen:

1. review akan sebuah produk

2. posting dalam forum

3. opini yang terkemuka

Pemasar harus menyadari pertumbuhan eWOM diantara konsumen dan strategi pemasaran untuk 
menggunakan pikiran yang singkat dan bergantung pada informasi yang beredar (Park et al., 2007).

Berdasarkan teori Heuristic-systematic model, orang menggunakan dua model memproses informasi ketika menyikapi suatu pesan yaitu proses sistematik dan proses heruristik. Proses heuristic diartikan sebagai bentuk keterbatasan dalam memproses informasi yang membutuhkan sedikit usaha dan lebih sedikit sumber. Proses sistematis terkait sebuah bentuk yang melibatkan banyak bentuk usaha komprehensif untuk menganalisis dan memahami informasi (Griffin et al., 2002:85). Tindakan yang berdasar pada proses sistematis cenderung permanen, sedangkan tindakan yang berdasar pada proses heuristic cenderung bisa berubuah. Dalam proses dari heuristic systematic model, orang-orang menggabungkan sisi heuristiknya (yaitu, aturan pembuatan keputusan yang sederhana) dan berbagai alasan seperti kurangnya motivasi, waktu, peluang atau kesempatan, dan juga pengetahuan akan suatu hal tertentu.

ELM dan HSM dijelaskan sebagai dua pendekatan proses (Harris dan Gupta, 2008), dimana keduanya menekankan pada dua proses pengelolaan informasi. Kondisi disini dimana rute central dalam ELM dan proses sistematis dalam HSM cenderung mirip keti rute pheripheral ELM menyalurkan model proses heuristic dalam HSM. Kedua teori ini berdasarkan pada "jumlah pemikiran yang ditujukan akan sebuah argumen, yang kemudian mengusulkan sebuah elaborasi berlanjut" (Gupta dan Harris, 2009:2), dimana kualitas usaha besar yang dilakukan dengan menilai semua informasi yang relevan menjadi motivasi lemah dalam menilai isyarat heuristic (Gupta dan Harris, 2009). Perbedaan utama dari dua teori yang ada disini terletak pada perbedaan waktu kejadiannya. Dua model proses dalam HSM beroperasi dengan bebas dan juga membutuhkan keterikatan secara simultan ketika dua mode dalam EML terhubung secara terbalik, aartinya, ketika salah satu variable naik, maka variable yang satu lagi menurun (Larson, 2010).

Berdasarkan paradigma teori yang ada, mengenai komunikasi eWOM, pembaca akan memutuskan pilihannya dikarenakan dia melihat review dari orang-orang yang ada dalam posting komunikasi eWOM (Send an Lerman, 2007).

Berdasarkan dari identifikasi teori, dimana memiliki keterikatan sosial yang lebih kuat dalam suatu kelompok, anggota dalam kelompok cenderung menganggap bahwa mereka terasingkan dari orang diluar (Sohn, 2009). Yang dimaksud mengikat kuat adalah kecenderungan untuk mengarahkan kepada perilaku mencari informasi aktif daripada sebaliknya. Di sisi lain, informasi dari sumber hemophilic lebih sering digunakan, namun beberapa sumber informasi terlihat tidak kredibel (Steffes dan Burgee, 2009). Model pengaruh sosial mengarahkan kepada orang-orang untuk bertukar eWOM diantara mereka untuk menghasilkan sebuah level individual dan perhatian sosial dalam sebuah grup. Wetzer et al. (2007) menyatakan bahwa satu motif akan WOM negative adalah keinginan untuk memperingatkan yang lain dan menguatkan ikatan sosial".

Teori sosiolinguistik menyatakan bahwa gender memainkan peran kunci dalam jaringan sosial, dimana terdapat perbedaan objek sosial bagi pria dan wanita untuk memposting eWOM. Pria ingin untuk melindungi dan meningkatkan kedudukan sosial merekan dengan bertukar informasi yang mereka ketahui dalam internet, sedangkan wanita memposting pesan online untuk membangun reputasi dengan mendapatkan dukungan sosial (Awad dan Ragowsky, 2008).

\section{Saluran eWOM}

Saluran eWOM adalah lokasi atau platform dimana eWOM berada. Litvin et al. (2008) telah mengembangkan dua model dimensional (secara interaktif dan pandangan komunikasi) untuk mengklasifikasikan saluran eWOM. Dalam paper ini, penulis mengadopsi klasifikasi yang lebih sederhana dengan mengelompkkan kedua level interaktifitas menjadi satu dan memishakan jaringan dengan kelompok komunikasi. Dengan menampilkan gambar 1, eWOM dapat dilihat dengan tiga sudut pandang komunikasi, disebut one-to-one, one-to-many, dan many-to-many ke dalam satu dimensi.

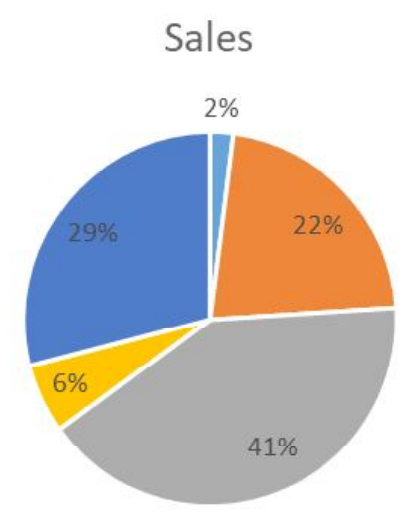

- one-to-one = many-to-many = one-to-many " others " nihil Gambar 3 Sudut pandang eWOM 
lebah dikenal mampu berkomunikasi dengan baik. Bahkan tumbuh-tumbuhanpun sepertinya mampu berkomunikasi. (QS. Al-Isra: 28).

\section{METODE PENELITIAN}

Penyusunan makalah ini dengan mereview dan mengklasifikasikan literatur terkait eWOM dengan menganalisis literatur eWOM dengan mempertimbangkan perkembangan kuantitatif dan isu-isu kualitatif yang bermanfaat bagi bidang akademik juga peneliti. Jurnal yang dianalisis diperoleh dengan cara mencari dan menggunakan artikel dari media online:

- Emeraldinsight.com

- Sciencedirect.com

Jurnal yang gunakan didapat dari kedua situs penyedia jurnal akademik tersebut. Situs tersebut penulis anggap layak dijadikan referensi karena jurnal dan artikel yang ada didalamnya telah terindeks internasional. Secara keseluruhan penulis menggunakan 94 artikel maupun jurnal yang digunakan untuk men-

Tabel 1 Sumber Jurnal

\begin{tabular}{lc}
\hline Sumber artikel & Jumlah \\
\hline Advances in Consumer Research & 5 \\
Decision Support Systems & 3 \\
Electronic Commerce Research and & \\
Applications & 4 \\
Electronic Markets & 4 \\
Information Systems Research & 3 \\
Interactive Advertising & 5 \\
International Journal of Electronic Commerce & 3 \\
International Journal of Research in Marketing & 5 \\
Internet Research & 3 \\
Journal of Advertising Research & 4 \\
Journal of Business Research & 6 \\
Journal of Computer-Mediated Communication & 3 \\
Journal of Electronic Commerce & 4 \\
Journal of Interactive Advertising & 5 \\
Journal of Interactive Marketing & 9 \\
Journal of Internet Commerce & 3 \\
Journal of Marketing Communications & 1 \\
Journal of Marketing Management & 4 \\
Journal of Marketing Research & 3 \\
Journal of Retailing & 3 \\
Journal of the American Society for Information & \\
Science \& Technology & 3 \\
Managing Service Quality & 2 \\
Marketing Science & 5 \\
Sosial Behavior and Personality & 4 \\
\hline Total & $\mathbf{9 4}$ \\
\hline Sumber: Data diolah & \\
\hline
\end{tabular}

Sumber: Data diolah

\section{Table 2 Metode Penelitian dalam eWOM}

\begin{tabular}{lcccc}
\hline Bentuk Penelitian & input & proses & output & total \\
\hline Case study & 0 & 2 & 1 & 3 \\
Content analysis & 0 & 5 & 8 & 13 \\
Content analysis and & & & & \\
interview & 0 & 0 & 1 & 1 \\
Experiment and survey & 0 & 1 & 1 & 2 \\
Experiment/simulation & 4 & 11 & 9 & 24 \\
Focus group, content & & & & \\
analysis and interview & 1 & 0 & 0 & 1 \\
Interview & 0 & 1 & 0 & 1 \\
Interview and case study & 1 & 0 & 0 & 1 \\
Literature review & 1 & 0 & 3 & 4 \\
Numerical analysis & 1 & 4 & 8 & 13 \\
Observation and survey & 1 & 0 & 0 & 1 \\
Survey & 8 & 3 & 9 & 20 \\
\hline Total & $\mathbf{1 7}$ & $\mathbf{2 7}$ & $\mathbf{4 0}$ & $\mathbf{8 4}$ \\
\hline Sumber: Datadiolah & & & &
\end{tabular}

Sumber: Data diolah

cari dan menganalis data terkait tujuan penulisan ini. Beberapa artikel tersebut menggunakan pendekatan empiris dalam penelitiannya seperti dengan menggunakan studi kasus, focus group, interview, observasi dan penelitan dengan data numerik.

\section{Analisis Teori atau Model Aplikasi}

Banyak contoh literatur sebelumnya menerapkan beberapa teori, seperti Elaboration Likelihood Model (ELM), Heuristic-Systematic Model (HSM), atribut teori dan efek sosial akibat suatu teori. Teori ELM dan HSM melihat bagaimana perbedaan dari proses pengaruh komunikasi persuasif (Cheung et al., 2009). Dari teori ELM menghasilkan perspektif teorits atas porses informasi komunikasi berdarkan review dari konsumen online. Dengan ELM, terdapat dua tipe proses informasi: rute sentral dan rute peripheral. Orang yang berada dalam rute sentral berpikir kritis dan berhati-hati terhadap semua informasi relevan sebelum menghasilkan suatu tindakan atau keputusan. Di sisi lain, orang yang berada pada rute peripheral tidak berpikir panjang meski dengan usaha minim dalam menghasilkan sebuah tindakan.

ELM menempatkan individu yang ingin memproses suatu pesan (berkeinginan memproses pesan) dan individu yang punya kemampuan untuk memproses pesan, cenderung tertarik pada suatu argument dan menghasilkan keinginan berkaitan dengan argument tersebut (Park et al., 2007). Namun, individu yang minim motivasi atau kemampuan dalam menanggapi informasi, cenderu memproses informasi dengan 
ibadah fardhu (salat, puasa, zakat dan haji) yang bertujuan untuk membentuk takwa. Sedangkan komunikasi dengan sesama manusia terwujud melalui penekanan hubungan sosial yang disebut muamalah, yang tercermin dalam semua aspek kehidupan manusia, seperti sosial, budaya, politik, ekonomi, seni dan sebagainya. Soal cara (kaifiyah) dalam Al-Quran ditemukan berbagai panduan agar komunikasi berjalan dengan baik dan efektif. Kaidah, prinsip, atau etika komunikasi Islam ini merupakan panduan bagi kaum muslim dalam melakukan komunikasi, baik dalam komunikasi intrapersonal, interpersonal dalam pergaulan sehari hari, berdakwah secara lisan dan tulisan, maupun dalam aktivitas lain (Rahmat, 1990). Dalam berbagai literatur tentang komunikasi Islam kita ditemukan setidaknya enam jenis prinsip bicara atau pembicaraan (qaulan) yakni (1) Qaulan Sadida; (2) Qaulan Baligha; (3) Qulan Ma'rufa; (4) Qaulan Karima; (5) Qaulan Layyinan dan (6) Qaulan Maysura.

Qaulan Sadida berarti pembicaran, ucapan, atau perkataan yang benar, baik dari segi substansi (materi, isi, pesan) maupun redaksi (tata bahasa). Dari segi substansi, komunikasi Islam harus menginformasikan atau menyampaikan kebenaran, faktual, hal yang benar saja, jujur, tidak berbohong, juga tidak merekayasa atau memanipulasi fakta. "Dan hendaklah takut kepada Allah orang-orang yang seandainya meninggalkan dibelakang mereka anak-anak yang lemah, yang mereka khawatir terhadap (kesejahteraan) mereka. Oleh sebab itu hendaklah mereka bertakwa kepada Allah dan hendaklah mereka mengucapkan Qaulan Sadida - perkataan yang benar" (QS. 4:9) "Hendaklah kamu berpegang pada kebenaran (shidqi) karena sesungguhnya kebenaran itu memimpin kepada kebaikan dan kebaikan itu membawa ke surga" (HR. Muttafaq 'Alaih).

Qaulan Baligha artinya menggunakan kata-kata yang efektif, tepat sasaran, komunikatif, mudah dimengerti, langsung ke pokok masalah (straight to the point), dan tidak berbelit-belit atau bertele-tele, seperti yang tersirat dalam QS. An-Nissa: 63 "Mereka itu adalah orang-orang yang Allah mengetahui apa yang di dalam hati mereka. Karena itu berpalinglah kamu dari mereka, dan berilah mereka pelajaran, dan katakanlah kepada mereka Qaulan Baligha (perkataan yang berbekas pada jiwa mereka)". Kata baligh berarti tepat, lugas, fasih, dan jelas maknanya. Agar komunikasi tepat sasaran, gaya bicara dan pesan yang disampaikan hendaklah disesuaikan dengan kadar intelektualitas komunikan dan menggunakan bahasa yang dimengerti oleh mereka. Rasulullah SAW bersabda "Berbicaralah kepada manusia sesuai dengan kadar akal (intelektualitas) mereka" (H.R. Muslim).

Qaulan Ma'rufa disebutkan Allah dalam QS. An-Nissa: 5 dan 8; QS. Al-Baqarah: 235 dan 263, serta QS. Al-Ahzab: 32. Qaulan Ma'rufa artinya perkataan yang baik, ungkapan yang pantas, santun, menggunakan sindiran (tidak kasar), dan tidak menyakitkan atau menyinggung perasaan. Qaulan Ma'rufa juga bermakna pembicaraan yang bermanfaat dan menimbulkan kebaikan (maslahat).

Qaulan Karima adalah perkataan yang mulia, dibarengi dengan rasa hormat dan mengagungkan, enak didengar, lemah-lembut, dan bertatakrama seperti yang ditunjukkan dalam QS. Al-Isra: 23. Dalam ayat tersebut perkataan yang mulia wajib dilakukan saat berbicara dengan kedua orangtua. Kita dilarang membentak mereka atau mengucapkan kata-kata yang sekiranya menyakiti hati mereka. Qaulan Karima harus digunakan khususnya saat berkomunikasi dengan kedua orangtua atau orang yang harus kita hormati. Dalam konteks jurnalistik dan penyiaran, Qaulan Karima bermakna mengunakan kata-kata yang santun, tidak kasar, tidak vulgar, dan menghindari "bad taste", seperti jijik, muak, ngeri, dan sadis.

Qaulan Layyina berarti pembicaraan yang lemah-lembut, dengan suara yang enak didengar, dan penuh keramahan, sehingga dapat menyentuh hati seperti yang ditunjukkan pada QS. Thaha: 44. Dalam Tafsir Ibnu Katsir disebutkan, yang dimaksud layyina ialah kata sindiran, bukan dengan kata-kata terus terang atau lugas, apalagi kasar. Ayat QS. Thaha: 44 adalah perintah Allah SWT kepada Nabi Musa dan Harun agar berbicara lemah-lembut, tidak kasar, kepada Fir'aun. Dengan Qaulan Layina, hati komunikan (orang yang diajak berkomunikasi) akan merasa tersentuh dan jiwanya tergerak untuk menerima pesan komunikasi kita. Dengan demikian, dalam komunikasi Islam, semaksimal mungkin dihindari kata-kata kasar dan suara (intonasi) yang bernada keras dan tinggi.

Qaulan Maysura bermakna ucapan yang mudah, yakni mudah dicerna, mudah dimengerti, dan dipahami oleh komunikan. Makna lainnya adalah katakata yang menyenangkan atau berisi hal-hal yang menggembirakan. Secara terminologis, komunikasi diartikan sebagai pemberitahuan sesuatu (pesan) dari satu pihak ke pihak lain dengan menggunakan suatu media. Sebagai makhluk sosial, manusia sering berkomunikasi satu sama lain. Namun, komunikasi bukan hanya dilakukan oleh manusia saja, tetapi juga dilakukan oleh makhluk-makhluk yang lainnya. Semut dan 
dan Chen, 2006). Dari penjelasan atau temuan tersebut bisa diartikan, keputusan pembelian seseorang dapat dipengaruhi oleh dua hal yaitu kualitas dari review konsumen akan produk tersebut, juga seberapa banyak orang yang telah mereview produk tersebut (Park et al., 2007).

Terdapat beberapa gagasan berbeda yang dihasilkan oleh para peneliti, mengenai jumlah dari review dan rata-rata hasil review yang dihasilkan. Beberapa peneliti menemukan bahwa kuantitas review memiliki pengaruh (Liu, 2006), sedangkan peneliti lain beranggapan bahwa rata-rata review yang dihasilkan, apakah itu positif atau negatif yang memiliki pengaruh signifikan (Dellarocas et al., 2007). Bagi pemberli dan penjual yang melakukan aktifitas transaksi di dunia online, biasanya cenderung tidak memiliki hubungan personal sebelum transaksi maupun interaksi lebih lanjut setelah transaksi, disini factor kepercayaan antar personal dan kredibilitas pemain tersebut memiliki peran yang krusial dalam keberhasilan transaksi tersebut (Zhou et al., 2009).

\section{Output}

Beberapa literatur yang membicarakan mengenai dampak dari eWOM dan pengaruhnya terhadap keputusan pembelian konsumen maupun penjualan suatu merek (Hu et al., 2008; Trusov et al., 2009; Dellarocas, 2006; Dellarocas et al., 2007). Park et al., 2007:128) mengemukakan bahwa konten pesan eWOM atau bisa dikatakan sebagai kualitas pesan tersebut dapat diartikan sebagai kualitas dari konten atau pesan yang disajikan untuk direview dalam sudut pandang karakteristik informasi (yang dimaksud adalah relevansi, kemudahan untuk dipahami, objektifitas). Park juga menemukan bahwa kualitas dan kuantitas dari review konsumen secara online adalah karakteristik penting yang mampu mempengaruhi konsumen dalam memproses suatu informasi, seperti adanya hubungan positif antara kualitas pesan dari eWOM dan keputusan konsumen untuk membeli barang atau jasa tersebut. Selanjutnya temuan tersebut juga menunjukkan hubungan signifikan antara review konsumen online dengan keinginan membeli (Park et al., 2007).

Jika online review yang dihasilkan cenderung logis dan memiliki unsur pesuasif, dengan berbagai alasan terkait produk tersebut, akan menyebabkan dampak positif bagi konsumen yang membaca pesan tersebut untuk melakukan keputusan pembelian akan produk tersebut. Selain itu, jumlah dari review yang dihasilkan oleh komunitas online tersebut juga memiliki hubungan positif terhadap keputusan konsumen untuk membeli produk tersebut. Berdasarkan penjelasan ini dapat dikatakan bahwa review yang tersaji dalam dunia online akan suatu produk akan mempengaruhi popularitas produk tersebut dalam bentuk apapun, semakin besar review yang dihasilkan, semakin besar pula ketertarikan dari konsumen untuk membeli, tentu berdasarkan informasi yang mereka dapatkan dari review online tersebut.

Melihat bagaimana bentuk komunikasi eWOM menjadi sumberdaya penting dan potensial bagi banyak konsumen pada era ini, pemasar meyakini bahkan tak sedikit yang mengaplikasikan website yang digunakan haruslah menampilkan konten yang lengkap dan menarik agar mampu merangsang pembaca pesan dengan tujuan untuk membangun suatu loyalitas terhadap merek itu sendiri. Sudut pandang pemasar yang seperti ini mempertimbangkan implikasi pemasarannya (Gelm dan Sundaram, 2002; Chen dan Xie, 2008) bersumber dari eWOM. Saat ini para pemasar dihadapkan pada tantangan tentang bagaimana menilai, mengaplikasikan, maupun menyikapi bagaimana eWOM tersebut dapat berjalan secara efektif. Pengamatan terhadap eWOM menjadi suatu hal yang menarik perhatian bagi para peneliti. Beberapa peneliti yang dimaksud seperti Godes dan Mayzlin (2004), Dwyer (2007) dan Ferguson (2008).

\section{Prinsip Komunikasi dalam Islam}

Prinsap dasar dari konsep eWOM ini adalah komunikasi. Kajian komunikasi secara mendasar tidak hanya disampaikan literatur konvensional yang ada. Bahkan komunikasi sendiri sebenarnya telah diajarkan oleh Allah SWT melalui kitabnya Al Qur'an tentang bagaimana pentingnya komunikasi bagi umat manusia khususnya umat Islam. Maka dalam makalah ini akan dibahas tentang komunikasi dalam perspektif Islam. Secara leksikal komunikasi adalah pengiriman dan penerimaan pesan atau berita antara dua orang atau lebih. Sehingga pesan yang dimaksud dapat dipahami. Komunikasi mempengatuhi perubahan perilaku, cara hidup kemasyarakatan, serta nilai-nilai yang ada. Perubahan-perubahan tersebut tampaknya berbanding lurus dengan perkembangan teknologi komunikasi.

Dalam perspektif Islam, komunikasi disamping untuk mewujudkan hubungan secara vertikal dengan Allah SWT juga untuk menegakkan komunikasi secara horizontal terhadap sesama manusia. Komunikasi dengan Allah Swt tercermin melalui ibadah- 
melibatkan motivasi dari penulis maupun pembaca eWOM. Apa yang membuat eWOM itu ada? Kondisi dimana penulis dan pembaca termotivasi untuk memposting dan mencari tahu eWOM dikarenakan ikatan sosial. Kekuatan dari ikatan yang dimaskud adalah level intensitas dari hubungan sosial antara konsumen atau beberapa individual yang memiliki hubungan teman yang bervariasi dalam jejaring sosial konsumen (Steffes dan Burgee, 2009:45). Keinginan dan ketertarikan sosial mempengaruhi tingkat partisipasi dari individu atau kelompok (Okazaki, 2009). Peneliti sebelumnya menyatakan bahwa hasrat atau keinginan konsumen terhadap interaksi sosial, keinginan/hasrat terhadap insentif ekonomi, perhatian teradap konsumen lain, dan potensi untuk meningkatkan harga diri mereka sendiri adalah factor utama yang mendorong perilaku eWOM. Maka dari itu pengguna eWOM bisa dikelompokkan dalam berbagai motif tentang apa yang memotivasi perilaku mereka. Oleh karena itu perusashaan perlu untuk menerapkan strategi berbeda untuk mengelola perilaku eWOM diantara pengguna produk atau jasa mereka (Hennig-Thurau et al., 2004).

Dalam berbagai kasus, penulis yang memposting eWOM melakukan posting karena mereka ingin berbagi opini dan pengalaman. Pembaca mencari eWOM karena mereka membutuhkan informasi mengenai harga, kualitas produk, resiko yang ada dan sebagainya. Internet memilik kemampuan untuk mempengaruhi proses mencari informasi oleh konsumen dalam berbagai level, termasuk seperti apa informasi yang dibutuhkan maupun informasi apa yang disajikan, juga seberapa penting informasi yang disajikan (Bakos dan Brynjolfsson, 2000; Kulviwa et al., 2004; Steffes dan Burgee, 2009). Biz Rate telah melakukan suatu survey terhadap 5.500 web konsumen, menemukan bahwa 44 persen dari keseluruhan responden tersebut mengatakan bahwa merekan telah saling mengkonsultasikan ataupun bertukar opini dalam situs tersebut sebelum melakukan suatu keputusan pembelian, dan 59 persen diantara mereka menghasilkan penilaian dari suatu merek atau apun itu dengan hasil yang lebih bermanfaat atau bernilai dari penilaian yang dilakukan oleh profesional (Piller, 1999).

Orang yang memiliki pengalaman akan suatu merek dan pengetahuan akan merek tersebut juga mampu menjadi penggerak dalam komunikasi eWOM, dimana pencari informasi membaca pesan eWOM untuk mengetahui informasi maupun opini orang lain dan juga pengalaman ketika penulis pesan mem- posting eWOM untuk berbagi pengalaman dan pengetahuan akan merek tersebut. Hal ini dianggap bahwa pengalaman yang tertuang dalam website akan meningkatkan kemungkinan dari pengguna internet dalam mencari informasi (Klein dan Ford, 2003). Orang dengan minim pengalaman dalam internet cenderung mencari informasi melalui jaringan tradisional. Gilly et al., 1998:85) mengemukakan opinion leader muncul untuk menerima lebih banyak informasi melalui sumber non-personal dari informasi tersebut dan juga banyak produk yang terlibat secara berkelanjutan; artinya mereka menjaga ketertarikan akan sebuah produk pada level yang tinggi dimana mereka ini adalah opinion leader itu sendiri.

Sebuah riset menyatakan bahwa opinion leader cenderung untuk menyebarkan informasi kepada para pencari informasi (Okazaki, 2009). Jika kita melihat eWOM sebagai suatu alat pemasaran, dan juga mempertimbangkan perkembangan dunia internet, pemasar dapat memanipulasi eWOM untuk mempengaruhi perilaku pembelian konsumen ataupun juga perilaku mereka dalam memutuskan suatu merek (Dellarocas, 2006).

\section{Process}

Proses dalam model ini terkait dengan platform, sistem, atau situs dimana eWOM diproses. Platform yang dimaksud adalah jaringan atau saluran dari eWOM, di mana lokasi eWOM, seperti forum diskusi, berita dalam grup dan lain-lain (Hennig-Thutau dan Walsh, 2013). Sistem, dan situs di sini diartikan sebagai mekanisme teknis dari eWOM itu, seperti sistem rekomendasi maupun agen-agen pencarian.

Pesan dari eWOM sendiri adalah ini dari proses tersebut, seberapa sukses pesan tersebut dapat berjalan. Hal ini terkait bagaimana pesan tersebut berjalan di luar apakah menghasilkan kesan positif atau negatif, lalu kualitas konten pesan, kebergunaan, kredibilitas, dan akurasi dari sasaran pesan tersebut. Selama proses tersebut dijalankan, eWOM berarti dalam proses dan telah dijalankan. Tak jauh beda dengan WOM, penelitian menunjukkan bahwa eWOM memliki kredibilitas, empati dan relevansi yang lebih tinggi ketimbang model pemasaran lain yang notabene sama-sama berbasi informasi di internet (Bickart dan Schindler, 2001).

Sebuah penelitian yang terfokus pada positif maupun negative review dari konsumen, salah satunya mengatakan bahwa apabila ada review positif dari konsumen, maka akan mempengaruhi pilihan produk dari konsumen akan produk tersebut (Huang 
Dengan berkembangnya teknologi informasi, situs jejaring sosial secara siginifikan mampu mengalirkan informasi dan saling bertukar informasi, di mana hal ini menjadi bentuk baru dari konvensional WOM. Jika WOM mampu menyampaikan pesan kepada sedikit orang karena keterbatasan waktu, melalui internet hal tersebut dapat disebarluaskan ke semua orang tanpa ada batasan, bahkan waktu yang sedikit juga tidak membatasi persebarannya. Hasilnya eWOM berperan penting kepada keputusan pembelian konsumen pada era sekarang ini.

Varadarajan dan Yadav (2002) berpendapat bahwa terdapat 4 perubahan penting yang terjadi dalam lingkungan pembelian sebagai dampak adanya eWOM:

1. Akses kepada atribut harga dan non-harga dari produk;

2. Pembanding alternative dan evaluasi dari review konsumen yang sudah beli;

3. Perkembangan kualitas informasi;

4. Informasi yang terorganisasi dan terstruktur.

Artinya eWOM merupakan tipe komunikasi dimana melibatkan tiga komponen utama: pengirim pesan, pesan itu sendiri, dan penerima pesan. Model Yale mengungkapkan ketiga faktor utama ini mempengaruhi perhatian dari partisipan, komprehensi, dan apakah pesan tersebut dapat diterima, dapat mempengaruhi opini, persepsi, dan tindakan (Cheung et al., 2009:13). Untuk mengonsep tindakan eWOM, penulis menganalisis hal tersebut mulai dari pandangan input-process-output (IPO) menuju teori komunikasi.
Komponen input, proses, dan output yang dimaksud terkait pengirim pesan, pesan, dan penerima pesan.

\section{Konsep eWOM: dengan pandangan IPO}

Makalah ini menempatkan tiga konsep dari kegiatan eWOM terkait konsep IPO (lihat gambar 1). Banyak peneliti mengadopsi IPO dalam penelitian perilaku organisasi (Bushnell, 1990). IPO diartikan sebagai input yang mengarahkan kepada proses yang selanjutnya mengarahkan ke output (Ilgen et al., 2005:519). Seperti yang ditampilkan dalam gambar 1, framework ini menjelaskan eWOM memiliki input, process, dan output. Ketiga tahapan ini menjadi penghubung batasan dari kerangka kerja ini (Turner, 2005) yang menggambarkan sumber atau pemicu sebelum komunikasi eWOM, proses, dan hasil dari komunikasi eWOM.

Konsep framework IPO digunakan sebagai model dasar yang menekankan input eWOM, mengarahkan pada proses yang mempengaruhi output dari eWOM pada perilaku konsumen. Proses ini dikelompokkan dalam tiga area yang mencakup sumber atau pemicu sebelum komunikasi eWOM, proses, dan hasil dari komunikasi eWOM (Litvin et al., 2008; Sweeney et al., 2008).

\section{Input}

Input dalam hal ini terkait dengan antesendan atau motif yang dipakau eWOM dan penggerak dari postingan dan membaca eWOM dimana hal ini

\begin{tabular}{|l|}
\hline \multicolumn{1}{|c|}{ Input } \\
1. Motivasi penulis \\
a. ikatan sosial \\
b. opinion leader \\
c. memberikan informasi \\
d. kredibilitas \\
e. pengalaman \\
f. pengetahuan \\
2. motivasi pembaca \\
a. ikatan sosial \\
b. opinion seeker \\
c. kebutuhan informasi \\
d. pengetahuan sebelumnya \\
e. resiko dari pembelian \\
3. motivasi pemasar \\
\hline
\end{tabular}

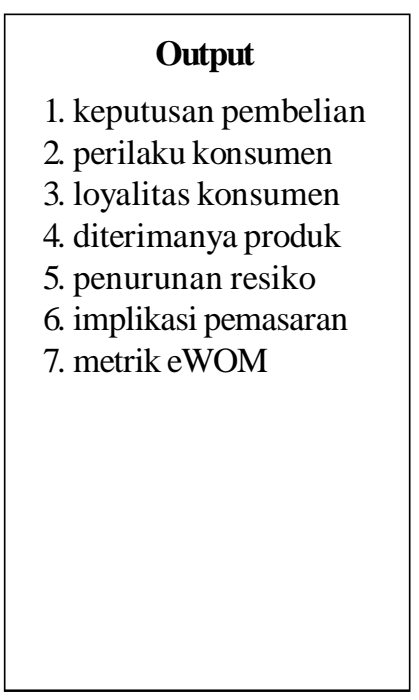

\begin{tabular}{|l|}
\multicolumn{1}{|c|}{ Process } \\
1. Platform eWOM \\
2. Sistem eWOM \\
3. Desain eWOM \\
4. Karakteristik pesan \\
a. eWOM positif/ \\
negative \\
b. volume \\
c. kualitas \\
d. kegunaan \\
e. kredibilitas \\
f. akurasi \\
5. Memproses informasi \\
eWOM \\
\end{tabular}

Gambar 2 Konseptual Framework eWOM 
Lee et al., 2014) dan mencari informasi akan eWOM (Goldsmith dan Horowitz, 2012).

Bentuk komunikasi eWOM menjadi sumberdaya penting dan potensial bagi banyak konsumen pada era ini. Pemasar meyakini bahwa aplikasi website yang digunakan haruslah menampilkan konten yang lengkap dan menarik agar mampu merangsang pembaca pesan dengan tujuan untuk membangun suatu loyalitas terhadap merek itu sendiri. Sudut pandang pemasar yang seperti ini mempertimbangkan implikasi pemasarannya (Chen dan Xie, 2008) bersumber dari eWOM dan saat ini para pemasar dihadapkan pada tantangan tentang bagaimana menilai, mengaplikasikan, maupun menyikapi bagaimana eWOM tersebut dapat berjalan secara efektif.

Pembahasan eWOM dengan media internet, di Indonesia dapat dilihat dari pengguna media sosial. Maraknya fenomena penggunaan sosial media di Indonesia tentu saja membuat para pemasar, pengusaha, organisasi maupun perusahaan mulai berlombalomba memanfaatkan sosial media sebagai media komunikasi untuk mempromosikan barang maupun jasa (sosial media marketing). Hal ini dikarenakan jangkauan sosial media sangat luas, tanpa batas dan berbiaya murah sehingga menjadikannya alternatif yang sangat menarik dalam melakukan promo melalui internet.

Data dari hasil penelitian Ipsos menunjukkan bahwa sekitar 85 persen populasi yang menggunakan internet, 62 persennya aktif di sosial media. Indonesia menempati posisi pertama dalam penggunaan sosial media. Data ini menunjukkan perhatian masyarakat Indonesia yang besar terhadap sosial media. Grafik mengenai penggunaan sosial media di dunia dapat dilihat pada Gambar 1.

Visit social networking sites /forums or blogs

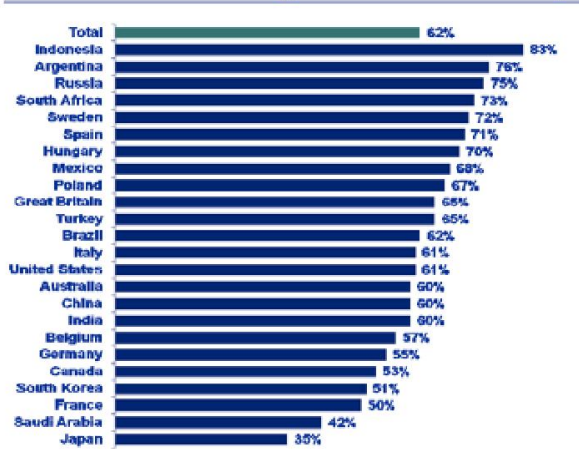

Gambar 1 Grafik penggunaan sosial media di dunia (Sumber: www.ipsos-na.com)
Grafik di atas dapat memberikan gambaran besarnya pangsa pengguna media sosial di Indonesia yang memberikan peluang bagi pemasar dalam membangaun eWOM.

\section{WOM dan eWOM}

Westbrook (1987:261) mengartikan WOM sebagai segala bentuk komunikasi informal yang diteruskan ke konsumen lain mengenai kepemilikan, manfaat, atau karakterisitik dari produk, jasa, atau merek tertentu. Harrison-Walker (2001:63) memahaminya sebagai bentuk informal komunikasi orang ke orang antara komunikator yang dianggap nonkomersil dengan penerima mengenai suatu merek, produk, organisasi atau jasa.

WOM awalnya dikenali sebagai satu dari beberapa hal yang berpengaruh atas perubahan suatu informasi (Breazeale, 2008; Godes dan Mayzlin, 2004; Maxha, dan NEtemeyer, 2002). Pengaruh dari WOM terhadap pembuatan keputusan konsumen telah diakui dalam literature akademik (Steffes dan Brgee, 2009). Berdasarkan literatur terdahulu, WOM lebih efektif ketimbang alat marketing lain dan media periklanan konvensional (Cheung et al., 2008). Oleh karenanya masalah ini menjadi hal penting dalam penelitian pemasaran. Namun WOM tradisional dibatasi oleh berbagai keterbatasan dan hanya akan berjalan efektif jika berada di dalam jaringan keterbatasan tersebut (Bhatanagar dan Ghose, 2004).

Konsep eWOM mulai menarik banyak perhatian dalam beberapa tahun terakhir bisa dikarenakan pertumbuhan internet dan popularitas dari e-commerce. eWOM juga dipahami sebagai bentuk komunikasi interpersonal pada era baru ini. Hal ini mampu menarik banyak peneliti untuk meneliti keterkaitannya dengan pemasaran dan konsumen, khususnya motif dibalik berjalannya eWOM dan dampak yang dihasilkan eWOM terhadap konsumsi (Cheung et al., 2008). Banyak peneliti tertarik untuk meneliti motif di belakang perilaku posting (mempublish sesuatu dalam dunia virtual) (Hennig-Thurau dan Walsh, 2013; Lee et al., 2014) dan mencari informasi akan eWOM (Goldsmith dan Horowitz, 2012). Bagaimana saluran, seperti komunitas online, yang memfasilitasi eWOM, mampu mempengaruhi persepsi akan barang atau jasa juga telah ditelliti (Subramani dan Rajagopalan, 2003). Penelitian ini mendiskusikan ancaman dan peluang yang muncul dengan tubuhnya pertukaran informasi secara online (Stauss, 1997, 2000). Berdasarkan uji coba, Senecal dan Nantel (2004) menjelaskan dampak dari eWOM mampu mempengaruhi pemilihan produk. 


\title{
PENERAPAN ELECTRONIC WORD OF MOUTH (eWOM) DAN PRINSIP KOMUNIKASI DALAM ISLAM
}

\author{
M. Fatkhur Rozi \\ Jurusan Manajemen Fakultas Ekonomi \\ UIN Maulana Malik Ibrahim Malang \\ Email: oyik_1976@yahoo.com
}

\begin{abstract}
This paper attempts to construct eWOM concepts based on input-process-output perspectives that produce a framework based on the identification of academic literature. This is based on the development of the internet world, e-commerce, and electronic word of mouth (eWOM) that is able to influence consumer behavior. The approach of this paper uses the literature review method of several journals relevant to the theme and study of communication principles in Islamic perspective and then discuss the data. The findings in this paper suggest that eWOM is relatively new. This is considered to be quite representative in the literature review regarding eWOM. The results of the review also get some research showing the theory that explains about eWOM phenomenon. The discussion not only aims to meet the gap in eWOM research but also produces an overview in analyzing eWOM communication. It can present a structured approach in researching various literatures and identify existing trends and gaps, aiming to find an overview in research on eWOM. The results can integrate the classification framework that can present the concept framework in other studies.
\end{abstract}

Keyword: E-Commerce, Electronics word of mouth, Principles of Communication in Islam

Perkembangan dari dunia teknologi khususnya internet perlu menjadi perhatian khusus saat ini. Banyak pengguna internet saat ini menggunakan satu atau bahkan lebih komunitas online, baik untuk berinteraksi maupun mencari informasi (Alboes et al., 2008). Internet menghasilkan suatu hal yang baru dan warna baru dalam jaringan global dengan adanya electronic word of mouth (eWOM) (Hennig-Thurau dan Walsh, 2013).

Teknologi informasi dan internet tidak hanya menghasilkan sebuah peluang bagi konsumen untuk membagi pendapat mereka mengenai barang atau jasa (Chen dan Xie, 2008; Avery et al., 2009) namun juga menjadi alat pemasaran baru. Terjadi perkembangan yang luar biasa dalam industri word of mouth (WOM) (WOMMA, 2010). Media online dan sosial media memiliki pengaruh yang besar terhadap pertumbuhan ini (Brown et al., 2007). Karena adanya perkembangan dalam dunia e-commerce, eWOM mulai menjadi perhatian bagi peneliti dan praktisi (Brown et al., 2007; Dwyer, 2007; Xia dan Bechwati, 2008). Penelitian menemukan bahwa perilaku belanja konsumen dalam jaringan internet dipengaruhi oleh eWOM. Peneliti lain juga menemukan bahwa orang menggunakan eWOM untuk mencari informasi yang dibutuhkan (Smith et al., 2014). eWOM diartikan sebagai berbagai bentuk statemen positif atau negatif yang diibuat oleh konsumen potensial dan aktual. (Hennig-Thurau et al., 2013). eWOM sebagai komunikasi orang ke orang secara informal yang dilakukan antara komunikator nonkomersil kepada penerima informasi mengenai merek, produk, organisasi atau layanan. Proses ini biasa terjadi di komunitas virtual dimana mereka terkesan telah membangun hubungan dengan orang lain padahal nyatanya tidak, namun mereka merasa terhubung dengan suatu ketertarikan atau topik yang sama (Cheong dan Morrison, 2008).

Konsep eWOM mulai menarik banyak perhatian dalam beberapa tahun terakhir bisa dikarenakan pertumbuhan internet dan popularitas dari e-commerce. eWOM juga dipahami sebagai bentuk komunikasi interpersonal pada era baru ini. Hal ini mampu menarik banyak peneliti untuk meneliti keterkaitannya dengan pemasaran dan konsumen, khususnya motif dibalik berjalannya eWOM dan dampak yang dihasilkan eWOM terhadap konsumsi (Cheung et al., 2008). Banyak peneliti tertarik untuk meneliti motif dibelakang perilaku posting (mempublish sesuatu dalam dunia virtual) (Hennig-Thurau dan Walsh, 2013; 